\title{
Ensuring the robustness of targeted briefs
}

\author{
Barbara Ghodse, Elizabeth Rang
}

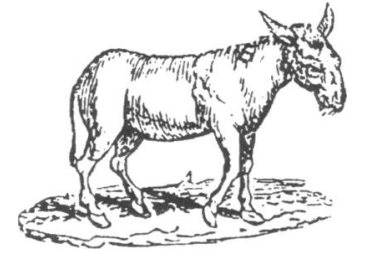

A major behavioural challenge

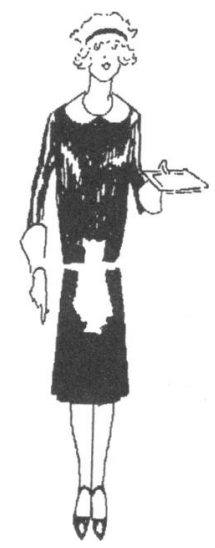

Frontline manager?

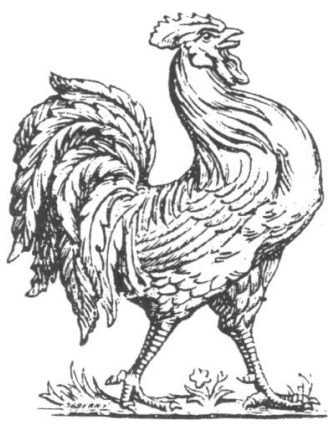

$A$ cock up it may be, but an inappropriate solution is what we call $i$

Merton and Sutton Health Authority, Wilson Hospital, Mitcham, Surrey CR4 4TP

Barbara Ghodse, district contracts manager Elizabeth Rang, consultant in public health medicine

Correspondence to: Dr Ghodse.

$B M 7$ 1993;307:1626-7
The NHS, like any other large organisation, has developed its own language, which may be difficult for outsiders and newcomers to understand. The following interpretation of a selection of words and phrases from this jargon may be helpful.

Achieving the spend: spending the year's budget in less than a year. Undesirable and can be prevented if hospitals pace activity: go slow.

Away Day (not a cheap rail ticket): the time for the WAY FORWARD to be revealed. Usually takes place in a comfortable hotel.

Brainstorming: a meeting with a flip chart, instead of minutes. Other types of meeting include: focus group a group that focuses, laser-like, on one issue; task group - a group that can only do one thing at a time; workshop-a talkshop; everyone attending should work (that is, talk); consensus conference-a BIG AND EXPENSIVE MEETING, lasting one or more days; everyone has the chance to have their two-penn'orth.

Bridging (not dentistry or engineering): money for an otherwise unaffordable project. Best if it is external (from the region or NHSME). Internal bridging means: find the money yourself. This may be achieved by CIPs (cost improvement programmes)-getting more done for less money; maximising appropriate use-being as efficient as possible; minimising cost-doing it as cheaply as possible (or not doing it at all); and targeting and prioritising resources-making cuts.

Caring for carers: token recognition of the fact that unpaid carers carry an enormous burden and that if they didn't the NHS and social services would collapse.

Challenge: problem. A major behavioural challenge is getting people to do something even if they know it is unnecessary, undesirable, and inappropriate.

Clarifying rules and regulations: the region or NHSME making up the rules a they go along.

Client/consumer/user/resident: patient, which is a better word because that is what they have to be with the NHS.

Consortium approach: one health authority does all the donkey work on behalf of several others.

Cost equals price: charge what you like because no one knows what anything costs.

Enable/empower: give an illusion of choice to users/ clients/carers/consumers/residents, etc, etc.

Executive summary: a one page summary (with bullet points) of a document (usually very glossy) that is so padded with jargon that no one can be bothered to read it. (Why say it in one page if you can say it in 20?)

Financial and policy context: "I don't know (or can't be bothered to explain) the background to this situation."

Flagship: Guy's Hospital. (Antonym is white elephant -the new Chelsea and Westminster).

\section{Glossary of important abbreviations}

CHC: community health council

ECR: extracontractual referral

HA: health authority

LA: local authority

NHSME: NHS management executive

Frontline managers: receptionists? Who are the backline managers?

Health needs assessment: an excuse to eliminate unaffordable health care.

Healthy alliances: safer sex.

Healthy dialogues: no swearing.

Hub and spoke: a big and important unit in the centre (the teaching hospital, naturally) to do the difficult (interesting) stuff, and smaller units/clinics out in the sticks doing routine work. A nice idea in principle, but will it become a treadmill for consultants as they rush from spoke to spoke and back to the hub?

Improve the weighted capitation position: give more money to the south coast, the shires, etc.

Inappropriate solutions which will have to be unpicked: a cock up.

Inappropriate use of institutional care: having anyone in hospital who could be at home; in a hostel or a bedsit; under Waterloo bridge.

Joint ownership: applies to problems, not assets.

Key players/stakeholders: people you must get on your side if you are going to achieve your objectives.

Knock-for-knock agreement: the funding is too difficult to sort out, so carry on as before.

Level playing field (nothing to do with Wembley or Twickenham): somebody else's perception of what's "fair"; used in the context of reorganisations.

Local voices: the $\mathrm{CHC}$ and MPs. Listen and respond.

Medical manpower: doctors; additional medical manpower-more doctors.

Mission statement: a must for every organisation; its raison d'être. A shining beacon, guiding every action. Can you hear the trumpets sounding?

Money following the patient (not a patient with a hole in his pocket): ok for ECRs. For block contracts, keep your fingers crossed that the reverse happens (patients following the money) or the contracts manager will have to resign.

Networking: talking (never gossiping) to colleagues.

Offshore: the Isle of Wight.

Organisational Sellotape: this is used to tack two organisations together prior to merger. (Health warning: cheap Sellotape is unreliable.)

Patient-focused care: what a novel notion! Who were we focusing on before? 




Mission statement: " $A$ shining beacon, guiding every action"
Promote positive health: ostentatiously do something that is good for you, like going jogging or eating brown bread? Can you promote negative health?

Purchasing intelligence: a contradiction in terms.

Resettlement plans: move clients/residents/patients out of the institutions where they have lived for years and that they probably regard as their homes.

Seamless care: care will be seamless when LAs do everything that HAs think they should. And vice versa. Until then, the holes in the seams will still need patching up.

Share: tell; pass the problem on to someone else. "I would like to share this with you" never means their last Rolo.

Smooth take off: no discernible change. Targeted briefs: $Y$ fronts.

Tight deadline: 12 noon today, or yesterday.

Top down, bottom up (not a strip wash in a youth hostel): involving the whole organisation.

Trolley wait: it's not the trolley we're concerned about, but the patient on the trolley.

Unavailable data: as in, "Region will not ask for unavailable data except where the NHSME require it." You will probably have to make the answer up.

Up front: say what you mean even if it isn't what others want to hear. This can be very irritating.

Vision day: 1993 version of an Away Day.

Readers may like to test their new found fluency by translating the following paragraph:

The robustness of the targeted brief for the hospital's discharge policy depends on frontline managers working top down and bottom up. Within the existing financial and policy context the flagship will be empowered to provide a seamless service for its users and carers with its resettlement plans preventing the inappropriate use of institutional care in future. In order to keep a level playing field, the key stakeholders will have a knock-for-knock agreement to permit money to follow the patient.

Answers on the back of a postage stamp please; a consortium approach is not allowed.

Contributions from colleagues at Merton and Sutton Health Authority are gratefully acknowledged.

\title{
Paradigm, parameter, paralysis of mind
}

\author{
Neville W Goodman
}

When Watson and Crick wrote their famous short paper in $1953^{1}$ they chose the word novel to describe the structure of DNA. This was apt; novel means "of a new kind or nature, previously unknown." The use of novel is now rife in scientific papers and the word is devalued. Of 211000 papers published in 1970 and searched by the PaperChase medical database, $0.047 \%$ had novel in the title. By 1980 the figure was $0.148 \%$, by 1990 -with 381000 papers- $0.525 \%$; and in 1992 , $0.96 \%$-almost one in every 100 papers-had novel in the title. Novel is in danger of becoming no more than its synonym, new. "A new idea may be original, but a novel idea is sparkling and ingenious": what word to use for sparkle when every nucleotide sequence is novel in the eyes of its discoverer?

Words are copied, as methods are, because they impress. Scientists do not copy methods slavishly, however impressive; they think about them first. Not so, too often, with words. Words induce paralysis of the mind. Novel is more impressive than new, so novel is preferred-even though a little thought (and a dictionary) shows a difference. Two novel words doomed to share its fate are paradigm and parameter.

\section{A paradigm ...}

Paradigm is a technical grammatical term for the pattern of inflection of a word, that is, the way a word changes with number, tense, mood, and gender. Thomas Kuhn used paradigm, at least when he first defined it, as a "term that relates closely to 'normal science' [where] 'normal science' means research firmly based upon one or more past scientific achievements [that supply] the foundation for its further practice."”3 Having defined the word, Kuhn could then write that those "whose research is based on shared paradigms are committed to the same rules and standards for scientific practice." To have used a more everyday word, such as ideas or beliefs, would not have been right: ideas is too weak; beliefs are not a good basis for science. Instead, Kuhn took a word from another discipline, linguistics, and redefined it for his purpose-that of discussing the development of scientific thought.

This is a form of metaphor. To use another metaphor, Kuhn's paradigm is a global word, not a local one. The global meaning is useful, but its devaluation is under way.

\section{... and its devaluations}

Consider this use of paradigm: "traditional or classical medicine has always coexisted with alternative therapies, both paradigms sharing the social function of palliating suffering, healing, and controlling biological disorders." It works here, although "systems" might be better. But later in the same article "medicine is unimaginative because it is incapable of conceiving explanations beyond the realm of the scientific paradigm." Now the writer is in difficulties. He invokes two paradigms, traditional medicine and alternative medicine, but by "the scientific paradigm" means no more than science. (The presumption that science is unimaginative is too ridiculous to be taken seriously.)

Defining one paradigm as the whole of traditional medicine is useful-it is global; but consider this, from an editorial about possible adjuvant drugs in anaesthesia, "early reports do not ... give hope that they will deliver the anticipated anaesthetic paradigm." Paradigms within paradigms: is there also a gene therapy paradigm or a clotbusting paradigm?

\section{A TRIPARTITE EXAMPLE}

A review of the control of breathing invokes three paradigms. Firstly, "Most researchers using reduced preparations typically interpret their data using the reductionist hypothesis as an operating paradigm"here, paradigm is unnecessary. The sentence loses nothing if rewritten. "Most researchers using reduced preparations typically interpret their data using the 